\title{
Comparison between different diagnostic tests used for bacterial vaginosis
}

\author{
Vasundhara ${ }^{1}$, Farooq U..$^{2}$ Najam R. ${ }^{3}$ \\ ${ }^{1}$ Dr Vasundhara, Assistant Professor, ${ }^{2}$ Dr. Umar Farooq, Professor \& Head, ${ }^{1,2}$ authors are affiliated with Department of \\ Microbiology, Teerthanker Mahaveer Medical College and Research Centre, Moradabad (UP), India, ${ }^{3}$ Dr. Rehana Najam, \\ Professor \& Head, Department of Obstetrics and Gynecology, Teerthanker Mahaveer Medical College and Research Centre, \\ Moradabad (UP) India.
}

Corresponding Author: Dr. Vasundhara, Assistant Professor, Department of Microbiology, TMMC \& RC, Moradabad (UP) India. E-mail Id: vasu2578@gmail.com

\begin{abstract}
Background: Bacterial vaginosis is the primary reason for unusual vaginal expulsion in females of fertile age resulting in poor pregnancy ending, pelvic seditious disease, chorioamnioitis, endometritis and increased susceptibility to HIV.As the prevalence is high, and usual investigative tests require laboratory expertise, a future study was therefore performed to compare different diagnostic methods for making an precise diagnosis of bacterial vaginosis. Materials and Methods: This study was conducted in Department of Microbiology which included females of reproductive age group, attending Obstetrics and Gynaecology OPD of TMMC \& RC, Moradabad, over a period of one year (March 2017- March 2018). A total of 400 patients with complaints of vaginal discharge and other associated complaints like pruritus, pain lower back, primary or secondary infertility were included in the study. Diagnosis of Bacterial vaginosis was done by using an array of both conventional techniques which included Gram's staining, Nugent's score, vaginal pH etc., and a newer diagnostic technique (OSOM BV Blue test). The patients were also examined PV and the relevant clinical findings were also noted. Results: Out of a total of 400 patients listed for the study, 240 were diagnosed as having bacterial vaginosis. Comparison of the different methods for the diagnosis of bacterial vaginosis revealed that bacterial vaginosis could be detected by 'clue cells' in 100\% patients, by OSOM BV Blue test in $97.6 \%$ patients, by Amsel's criteria in $67.1 \%$ patients, and by evaluation of vaginal $\mathrm{pH}$ and vaginal amines in $63.4 \%$ and $62.2 \%$ patients respectively. Conclusion: Different diagnostic techniques have varied sensitivity and specificity in diagnosis of bacterial vaginosis. OSOM B.V. blue test is found to be highly sensitive and can be performed easily in clinical settings where microscopic facilities are not available.
\end{abstract}

Keywords: Diagnosis, Bacterial Vaginosis, Gram’s Staining, Nugent's Score, Vaginal pH, OSOM BV Blue Test.

\section{Introduction}

Bacterial vaginosis (BV) is a regular clinical condition in women of fertile age [1]. It is conventionally appreciated as a temporary community disturbance of the vaginal microbiota, though really involving self-organization as a resilient biofilm community [2]. BV is a condition where the normal flora of the vagina is disturbed and replaced by an extra-growth of certain microbes or it is associated with an imbalance in the bacteria that are usually present in a woman's vagina. The vagina normally contains mostly "healthy" bacteria, and fewer "harmful" bacteria, BV develops when harmful bacteria outnumbers healthy bacteria [1]. The etiological bacteria are Anaerobic bacteria (Prevotella, Mobiluncus, Gardnerella vaginalis, Ureaplasma, Mycoplasma) [3]. It depicts an exceptional and difficult change in the flora of the vagina, which is characterized by a reduction in the occurrence and the

Manuscript received: $10^{\text {th }}$ October 2019

Reviewed: $20^{\text {th }}$ October 2019

Author Corrected: $26^{\text {th }}$ October 2019

Accepted for Publication: $30^{\text {th }}$ October 2019 numbers of lactobacilli and a rise in the concentration of Gardnerella vaginalis and resident anaerobic bacteria [1]. The most common types of lactobacilli in the vagina include Lactobacillus crispatus, L. jensenii, L. gasseri, and L. iners. Most of these lactobacilli act as important hostdefense mechanisms against BV by secreting substances that inhibit the growth of microbial pathogens and indigenous anaerobes [4]. Clinical features were first described by Gardner and Dukes [5] and range from asymptomatic to an increased thin vaginal discharge with or without a fishy odour. Some women with bacterial vaginosis have a foul smelling, thin, uniform frothy, vaginal exonerate $[1,6]$.

There are a number of pregnancy and/or gynecological complications associated with BV. Specifically, BV has been associated with both STI and non-chlamydial, nongonococcal pelvic inflammatory disease [7]. The contributing risk factors for BV comprises of low

Pathology Update: Tropical Journal of Pathology \& Microbiology Available online at: www.medresearch.in 838 | P a g e 
socioeconomic status, vaginal douching, smoking, new or multiple sex partners, unprotected intercourse and women who have sex with women [3]. BV increases chances of receptiveness to HIV infection and other Sexually transmitted diseases, such as herpes simplex virus (HSV), chlamydia and gonorrhoea.

As it is just an extra-growth of the unhealthy flora of the vagina devoid of swelling, there is no single best method for the diagnosis of bacterial vaginosis $[1,6]$ This condition is defined by a composite of four clinical criteria: (1) Vaginal discharge is homogeneous; (2) vaginal discharge had a $\mathrm{pH} \geq 4.7$; (3) vaginal discharge had an amine-like odor when mixed with $10 \%$ potassium hydroxide; (4) vaginal discharge contained clue cells representing $\geq 20 \%$ of vaginal epithelial cells [8].

Although Gram stain is considered the diagnostic standard, bacterial vaginosis is traditionally diagnosed using the Amsel criteria [3] Criteria include thin, homogenous discharge; a positive whiff test; the presence of clue cells on microscopy; and a vaginal $\mathrm{pH}$ greater than 4.5. However, many a times, multiple criteria are used for the conclusion of bacterial vaginosis.

Even though, bacterial vaginosis (BV) is a common but highly enigmatic condition which is associated with adverse outcomes for women and their neonates [9] As the prevalence is high, and regular diagnostic tests require laboratory expertise, in view of this, the present prospective study was therefore performed to evaluate different diagnostic methods for making an exact diagnosis of bacterial vaginosis.

\section{Methods and Materials}

The study was conducted among 400 females of reproductive age group with complaints of vaginal discharge attending OPD of Gynaecology and Obstetrics, in association with Department of Microbiology, TMMC \& RC, Moradabad, over a period of one year (March 2017March 2018).

Study setting: OPD of Gynaecology and Obstetrics, TMMC \& RC, Moradabad Duration of study: 18 months. Duration: Over a period of one year (March 2017-March 2018).

Study description: Design: Prospective, observational study

Sample size: 400 selected randomly

Sample size justification: Sample size of the study was determined using SAS 9.2 package.

Minimum sample required to have $80 \%$ power to detect change of mean 5 and SD 3.5 at alpha $=0.05$.
Ethical approval: This study was approved by Institutional Ethics Committee (IEC) of a tertiary center in a teaching hospital.

Inclusion criteria: Patients with complaints of vaginal discharge and other associated complaints like pruritus, pain lower back, primary or secondary infertility were included in the study.

Exclusion criteria: Women with history of receiving systemic antibiotic therapy or local vaginal antimicrobial therapy within the preceding 15 days, who were menstruating at the time of the examination, vaginal bleeding, placenta previa, spermicide use, recent douching, or sexual intercourse within 24 hour.

Methodology: Diagnosis of BV was done using an array of conventional techniques which included Gram's staining, Nugent's score, vaginal $\mathrm{pH}$ and a newer diagnostic technique (OSOM BV Blue test). The patients were also examined PV and the relevant clinical findings were also noted.

\section{Data collection}

\section{Specimen collection}

Following a history and physical examination, vaginal fluid was collected from posterior fornix of the patient's vagina by using sterile swabs. Sample was taken from vagina of patient using sterile cotton swabs. Two swabs were taken from every patient.

- First swab: - used for gram staining

- Second swab: - used for OSOM BV BLUE test.

1) On Gram staining Clue cells i.e. epithelial cells with adhering gram-negative small rods and gram variable cocco-bacilli were seen. In bacterial vaginosis usually, there were very few or no pus cell and lactobacilli were not seen. Gram-positive cocci were also seen.

2) The OSOM BV BLUE Test ${ }^{\circledR}$ is an enzyme activitybased test based on activity of sialidase enzyme in vaginal fluid specimens, an enzyme produced by bacterial pathogens, such as, Gardnerella vaginalis, Bacteroides spp., Prevo tella spp., and Mobiluncus spp.

This test procedure contains a color producing substrate for bacterial sialidase enzyme. In this method, a vaginal fluid sample is placed in the BV Test. The sample then reacts with the color producing substrate. A Developer Solution is poured after the reaction. If the sample has increased level of sialidase activity (positive), a blue or green colour will be seen in BV Test container or in the swab head. If the sample has no sialidase activity (negative), or has very low levels, a yellow colour will be seen in the BV Test container. 
pH Test: Vaginal $\mathrm{pH}$ was tested with a $\mathrm{pH}$ paper held with a forcep and dipped into the vaginal secretion. Colour change was noted. $\mathrm{pH}>4.5$ is considered positive for bacterial vaginosis [10].

\section{Data analysis}

- Sensitivity and specificity were calculated for each testing method using the following formulas:

- Sensitivity: (number of true positives/(number of true positives + number of false negatives $))^{*} 100$;

- Specificity: (number of true negatives/(number of true negatives + number of false positives) $) * 100$.
Statistical analysis: Data were analysed using SPSS V 15.0 (Statistical Package for Social Sciences, Version 15.0) package. Data were given as Mean and SD for quantitative variables and Number (Percentage \%) for qualitative variables.

Chi square tests were applied to compare percentages of more than 2 groups and Fisher Exact Probability tests were applied to compare percentages between 2 groups.

All tests were 2 tailed. Level of Significance was taken as $\mathrm{P} \leq 0.05$.

\section{Result}

Out of a total of 400 patients enrolled for the study, 240 were diagnosed as having bacterial vaginosis (Table 1). The maximum number of patients (51.3\%) were in the age group 21-30 years, followed by 154 (38\%) patients in the 31-40-year age group. The highest prevalence of bacterial vaginosis was also seen in these age groups, $27.7 \%$ in the $31-40$-year age group as compared to $26.4 \%$ in the age group 21-30 years.

he most usual presenting complaints in patients in whom bacterial vaginosis was present were discharge PV (64.7\%), discharge PV with pruritus (83.3\%), and discharge PV with pain lower abdomen (91.2\%). It was also noted that bacterial vaginosis was significantly more common in pregnant females $(86.6 \%)$ as compared to non-pregnant females $(13.4 \%)$, and this difference was clinically significant $(\mathrm{p}<0.001)$.

Table-1: Distribution of total cases as diagnosed by OSOM BV Blue Test.

\begin{tabular}{|l|c|}
\hline Bacterial vaginosis & Number of patients (\%) \\
\hline Absent & $160(40)$ \\
\hline Present & $240(60)$ \\
\hline Total patients & $400(100)$ \\
\hline
\end{tabular}

Comparison of the different methods for the diagnosis of bacterial vaginosis revealed that bacterial vaginosis could be detected by 'clue cells' in $100 \%$ patients, by OSOM BV Blue test in $96.7 \%$ patients, by Amsel's criteria in $68.8 \%$ patients, and by evaluation of vaginal $\mathrm{pH}$ and vaginal amines in $65 \%$ and $60 \%$ patients respectively (Table 2). It is important to note that the 'clue cells' were consistently observed in all (100\%) patients, and they were absent in all the patients who were negative for bacterial vaginosis. Similarly, the OSOM BV Blue test ${ }^{\circledR}$ was also very accurate, giving a sensitivity of $96.7 \%$ and a specificity of $97.5 \%$. The difference between the sensitivity and specificity of the OSOM BV Blue test and Gram's staining was statistically significant $(\mathrm{p}<0.001)$ (Table 2). Out of a total of 400 patients, $42.5 \%$ were detected by Amsel's criteria, whereas Gram's staining detected $60 \%$ patients.

Table-2: Cross tabulation showing patients with bacterial vaginosis as detected by various tests and their co-relation with Gram's staining.

\begin{tabular}{|c|c|c|c|}
\hline Test done & $\begin{array}{c}\text { Results in patients with bacterial } \\
\text { vaginosis by Gram's staining } \\
(\mathbf{n}=\mathbf{2 4 0})\end{array}$ & $\begin{array}{c}\text { Results in patients without } \\
\text { bacterial vaginosis by Gram's } \\
\text { staining } \\
(\mathbf{n}=\mathbf{1 6 0})\end{array}$ & $\begin{array}{c}\text { Total patients } \\
\mathbf{( n = 4 0 0 )}\end{array}$ \\
\hline OSOM BV Blue test & $232(96.7)$ & $6(3.8)$ & $238(59.5)$ \\
\hline Vaginal pH $>4.5$ & $156(65)$ & $19(11.9)$ & $175(43.8)$ \\
\hline Amine test & $149(60)$ & $22(13.8)$ & $171(42.6)$ \\
\hline Clue cells & $240(100)$ & $0(0)$ & $240(60)$ \\
\hline Amsel's criteria & $102(42.5)$ & $15(9.4)$ & $117(42.8)$ \\
\hline
\end{tabular}




\section{Discussion}

Bacterial vaginosis is the most common cause of vaginal discharge among women of reproductive age group. It is an extremely common health problem for women, occurring in $35 \%$ of women attending sexually transmitted infections clinic, $15-20 \%$ of pregnant women and $5-15 \%$ of women attending gynaecology clinics [11]. In the present study, $240(60 \%)$ out of 400 patients were diagnosed as having bacterial vaginosis. This high prevalence may be due to inclusion of only symptomatic group in the present study.

In India different workers reported varying prevalence of bacterial vaginosis. In a study done in Karnataka, India, prevalence of bacterial vaginosis using Nugent's criteria was reported to be $20.5 \%$ [6]. Prasad et al [12] found the rate of bacterial vaginosis in young married women in Tamil Nadu to be $18 \%$, Agarwal et al [13] reported the prevalence of bacterial vaginosis in $21.7 \%$ cases, Bhalla et al [14] reported the occurrence, of bacterial vaginosis in $32.8 \%$ cases whereas, Dadhwal et al [15] reported bacterial vaginosis in $8.6 \%$ cases. In similar studies done by Saleem et al [10] and Naqvi et al [16] the prevalence of bacterial vaginosis was found to be $55.4 \%$ and $47 \%$ respectively. Anh et al [17] reported the prevalence of bacterial vaginosis as $3.5 \%$ in Vietnam whereas Jones et al reported the prevalence of bacterial vaginosis in Peru as $27 \%$ [18].

In the present study, based on Nugent's score by gram's staining, bacterial vaginosis (score $>7$ ) was found in $60 \%$ of women, and deviation from normal commensal flora (score 4-6) was found in $26.9 \%$ cases. Bhalla et al [14] reported bacterial vaginosis in $32.8 \%$ and intermediate flora in $16.9 \%$ women, whereas Sewankambo et al [19] reported bacterial vaginosis in $50.8 \%$ and intermediate flora in $31.7 \%$ women.

A study by Coleman JS et al [20] reported bacteria that were frequently detected in women with BV that included Gardnerella vaginalis, Atopobium vaginae, Megasphaera types, Leptotrichia amnionii, Sneathia sanguinegens, Porphyromonas asaccharolytica, a bacterium related to Eggerthella hongkongensis, and bacteria related to Prevotella species. Less frequently detected bacteria included Peptostreptococcus spp., Aerococcus, Anaerococcus, Gemella, and Veillonella genera.

Gram's Method of staining is simple, inexpensive, sensitive, specific and reproducible way to diagnose bacterial vaginosis [21,22] Conventional diagnostic methods such as gram staining based on Nugent scoring systemare popular [23] Amsel's criterion is also a standard method which provides accurate rapid diagnosis and has been used in many studies evaluating bacterial vaginosis [22].
However, recently, OSOM BV blue test with almost equally efficacious, less time consuming and minimal technical expertise requiring is emerged for rapid diagnosis of bacterial vaginosis. OSOM BV blue test is based on the principal of detection of bacterial sialidase activity (an enzyme produced by bacterial pathogens such as Gardnerella vaginalis, Bacteroides spp., Prevotella spp., and Mobiluncus spp.) in vaginal discharge [24].

Bacterial vaginosis as diagnosed by OSOM BV Blue test ${ }^{\mathbb{B}}$ in the present study was $58 \%$ (232 out of 400 patients). In the present study, sensitivity and specificity of OSOM BV Blue test ${ }^{\mathbb{B}}$ as compared to Gram's staining was found to be $97.6 \%$ and $97.5 \%$ respectively which is quite similar as reported by Myziuk et al [25] who demonstrated sensitivity and specificity of BV blue test ${ }^{\circledR}$ as $91.7 \%$ and $97.8 \%$ respectively. A study was conducted by Mahajan $\mathrm{G}$ et al [26] on 200 cases complaining of vaginal discharge. Of these, 68 (34\%) were diagnosed by BV blue test. Shujatullah F et al [24] in a similar study observed that OSOM BV blue test showed good efficacy, as compared with gram staining in diagnosing $\mathrm{BV}$ and thus, the performance of OSOM BV blue was better than the methods based on Amsel's criteria.

Madhivanan $P$ et al [27] examined the performance of the BVBlue POC test as compared to Amsel's criteria and Nugent scoring of Gram stains among women with and without symptoms of BV. Their results showed that BVBlue test had poor sensitivity in detecting BV (38.1\%) but was highly specific $(92.7 \%)$ in a population of women attending a reproductive health clinic in Mysore, India. In a study by Khatoon $\mathrm{R}$ et al [28] bacterial vaginosis was detected in $60.8 \%$ of patients. OSOM BV Blue test detected maximum number of cases with sensitivity and specificity of 95.3 and $92.1 \%$, respectively.

There is a great need for an inexpensive diagnostic method that is both reliable and unifies clinical and microbiological parameters to make it more sensitive while retaining its specificity [26] Thus, B. V. blue procedure can be used as a point-of-care test useful in making rapid and accurate diagnosis of bacterial vaginosis in setups lacking microscopic facilities or technical expertise.

The limitation of the present study is that it is an institutionbased study; further cross-sectional surveys with larger populations are required. As with most diagnostic tests, BV Blue has limitations. Since mixed vaginal infections may occur, the presence of sialidase activity does not rule out the presence of yeast, $T$. vaginalis, or other organisms. To prevent adverse performance of BV Blue, it should not be used in women who have recently douched, engaged in

Pathology Update: Tropical Journal of Pathology \& Microbiology Available online at: www.medresearch.in 841 | P a g e 
vaginal sexual intercourse, or used spermicides, vaginal lubricants, or feminine deodorant sprays within 72 hours prior to testing. BV Blue is a quick and easy test that detects the presence of sialidase activity by utilizing a chromogenic substrate of bacterial sialidase to produce a color reaction when a color developer solution is added to the reaction vessel. BV Blue appears to be a useful point-of-care tool to provide presumptive diagnostic information for women with $\mathrm{BV}$ when used in conjunction with clinical and patient information [25].

\section{Conclusion}

Different diagnostic techniques have varied sensitivity and specificity in diagnosis of bacterial vaginosis. OSOM B.V. blue procedure is a point of care procedure which can be easily done without expertise and lab facilities, still showed high sensitivity and specificity.

\section{What this study adds to existing knowledge?}

The study adds with most diagnostic tests, BV Blue has limitations. Since mixed vaginal infections may occur, the presence of sialidase activity does not rule out the presence of yeast, $\mathrm{T}$. vaginalis, or other organisms.

\section{Author's contribution}

Dr. Vasundhara: Contributed in design of this work, collection of data and editing.

Dr. Farooq U: Conception of the idea and collect data.

Dr. Rehana Najam: Contributed in writing manuscript and analyze the data.

Funding: No funding sources

Conflict of interest: None declared

Ethical Approval: This study was approved by the Institutional Ethics Committee

\section{References}

1. Sobel JD. Bacterial vaginosis. Annu Rev Med. 2000;51: 349-356. doi: 10.1146/annurev.med.51.1.349.

2. Verstraelen H, Swidsinski A. The biofilm in bacterial vaginosis: implications for epidemiology, diagnosis and treatment: 2018 update. Curr Opin Infect Dis. 2019;32(1): 38-42. doi: 10.1097/QCO.0000000000000516.

3. Paladine HL, Desai UA. Vaginitis: Diagnosis and Treatment. Am Fam Physician. 2018;97(5):321-329.

4. Ravel J, Gajer P, Abdo Z, Schneider GM, Koenig SS, McCulle SL, et al. Vaginal microbiome of reproductive-age women. Proc Natl Acad Sci U S A. 2011 Mar 15;108(1): 4680-4687. doi: 10.1073/pnas.1002611107. Epub 2010 Jun 3 .
5. Gardner HL, Dukes CD. Haemophilus vaginalis vaginitis: a newly defined specific infection previously classified non-specific vaginitis. Am J Obstet Gynecol. 1955; 69(5):962-976. doi: https://doi.org/10.1016/00029378 (55)90095-8.

6. Rao PS, Devi S, Shriyan A, Rajaram M, Jagdishchandra K. Diagnosis of bacterial vaginosis in a rural setup: comparison of clinical algorithm, smear scoring and culture by semiquantitative technique. Indian J Med Microbiol. 2004;22(1):47-50.

7. Money D. The laboratory diagnosis of bacterial vaginosis. Can J Infect Dis Med Microbiol. 2005;16(2):7779. doi: $10.1155 / 2005 / 230319$.

8. Eschenbach DA, Hillier S, Critchlow C, Stevens C, DeRouen T, Holmes KK. Diagnosis and clinical manifestations of bacterial vaginosis. Am J Obstet Gynecol. 1988; 158 (4): 819-828. doi: 10.1016/0002-9378 (88)900 $78-6$

9. Srinivasan S, Morgan MT, Fiedler TL, Djukovic D, Hoffman NG, Raftery D, et al. Metabolic signatures of bacterial vaginosis. MBio. 2015;6(2). pii: e00204-15. doi: 10.1128/mBio.00204-15.

10. Saleem N, Ali HS, Hussin R. Prevalence of Bacterial Vaginosis in pregnant women and efficacy of rapid diagnostic tests in its diagnosis. Infect Dis J Pakistan. 2006:93-95.

11. Grewal N, Mahajan A, Bajaj JK. The effect of supplementation of standard antibiotic therapy with oral probiotics for bacterial vaginosis. Int J Med Den Sci. 2018;7(1):1628-1631.

12. Prasad JH, Abraham S, Kurz KM, George V, Lalitha MK, John R, et al. Reproductive tract infections among young married women in Tamil Nadu, India. Int Fam Plan Perspect. 2005;31(2):73-82. doi: 10.1363/ifpp.31.73.05.

13. Agarwal S, Sharma V, Sarin R. Reproductive tract infections in women-prevalence HIV seropositivity and role of conventional methods in diagnosis. Ind J Sex Transmit Dis. 2005;26(2):73-77.

14. Bhalla P, Chawla R, Garg S, Singh MM, Raina U, Bhalla R, et al. Prevalence of bacterial vaginosis among women in Delhi, India. Indian J Med Res. 2007;125(2):167172.

15. Dadhwal V, Hariprasad R, Mittal S, Kapil A. P523 Prevalence of bacterial vaginosis in pregnant women and predictive value of clinical diagnosis. Arch Gynecol Obstet. 2010;281(1):101-104. doi: 10.1007/s00404-0091089-x. Epub 2009 Apr 19. 
16. Naqvi SH, Mirza SH, Masood S, Faheem Q. The Infectious etiologies of vaginitis in patients of vaginal discharge. Pak J Pathol 2007;18(3):79-82.

17. Anh PK, Khanh NT, Ha DT, Chien DT, Thuc PT, Luong $\mathrm{PH}$, et al. Prevalence of lower genital tract infection among women attending maternal and child health and family planning clinics in Hanoi, Vietnam. Southeast Asian J Trop Med Public Health. 2003;34(2):367-373.

18. Jones FR, Miller G, Gadea N, Meza R, Leon S, Perez J, et al. Prevalence of bacterial vaginosis among young women in low-income populations of coastal Peru. Int J STD AIDS. 2007;18(3):188-192. doi: 10.1258/ 095646 207780132505.

19. Sewankambo N, Gray R H, Wawe M J, Paxton L, Mc Nairn D, Wabwire-Mangen F. HIV-1 infection associated with abnormal vaginal flora morphology and bacterial vaginosis. Lancet 1997;350(9077):546-550. doi: https:// doi.org /10.1016/S0140-6736(97)01063-5.

20. Coleman JS, Gaydos CA. Molecular Diagnosis of Bacterial Vaginosis: an Update. J Clin Microbiol. 2018 Aug 27; 56 (9). pii: e00342-18. doi: 10.1128/JCM.00342-18. Print 2018 Sep.

21. Briselden AM, Moncla BJ, Stevens CE, Hillier SL. Sialidases (neuraminidases) in bacterial vaginosis and bacterial vaginosis-associated microflora. J Clin Microbiol. 1992; 30(3):663-666.

22. Tam MT, Yungbluth M, Myles T. Gram stain method shows better sensitivity than clinical criteria for detection of bacterial vaginosis in surveillance of pregnant, lowincome women in a clinical setting. Infect Dis Obstet
Gynecol. 1998; 6(5):204-208. doi: http://dx.doi.org/ 10. $1155 / \mathrm{S} 1064744998000416$.

23. Nugent RP, Krohn MA, Hillier SL. Reliability of diagnosing bacterial vaginosis is improved by a standardized method of gram stain interpretation. J Clin Microbiol. 1991;29(2):297-301.

24. Shujatullah F, Khan HM, Khatoon R, Rabbani T, Malik A. An evaluation of OSOM BV blue test in the diagnosis of bacterial vaginosis. Asian Pacific J Trop Med. 2010;3(7): 574-576. doi: https://doi.org/ 10.1016/S1995-7645(10) 60139-3

25. Myziuk L, Romanowski B, Johnson SC. BVBlue test for diagnosis of bacterial vaginosis. J Clin Microbiol. 2003;41(5):1925-1928. doi: 10.1128/jcm.41.5.1925-1928. 2003.

26. Mahajan G, Mahajan A, Chopra S, Chand K. Comparison of Different Diagnostic Methods of Bacterial Vaginosis-Amsel's vs Neugent. Int J Curr Microbiol App Sci. 2017;6(5):1442-1448. doi: https://doi.org/ 10. 20546/ ijcmas.2017.605.158.

27. Madhivanan P, Krupp K, Li T, Ravi K, Selezneva J, Srinivas V, et al. Performance of BVBlue rapid test in detecting bacterial vaginosis among women in Mysore, India. Infect Dis Obstet Gynecol. 2014;2014;908313. doi: $10.1155 / 2014 / 908313$.

28. Khatoon R, Jahan N, Ahmad S, Rabbani T. Comparison of OSOM BV Blue test with conventional methods for diagnosis of bacterial vaginosis. Af J Microbiol Res. 2013;7(28): 3698-3703. doi: 10. 5897/ AJMR2013. 5830 .

\section{How to cite this article?}

Vasundhara, Farooq U, Najam R. Comparison between different diagnostic tests used for bacterial vaginosis. Trop J Path Micro 2019;5(11):838-843.doi:10.17511/jopm.2019.i11.01 